\title{
Faculty Perception and Readiness to Engage in Initiatives towards Excellence
}

\author{
Zahedi, $M^{1}$, AlShehri, $M^{2,4}$, Al-Hadlaq, $S^{3}$, Jarallah, $N^{1}$, AlNaami, $M^{4}$, and AlZahrani, $A^{1}$
}

\begin{abstract}
Background: King Saud University (KSU) strives to become a university of first choice among top students, a 'university of tomorrow', globally competitive, and stands among the top in the region. KSU recognizes the challenges ahead, and implemented strategies to push the university forward.

Objectives: To identify the readiness of faculty members of medical and health colleges of KSU in realizing the inspirations of the university.

Methods: Respondents had either face-to-face interviews or answered an online questionnaire. Ninety-eight (98) or 7\% faculty members responded to the survey. The questionnaire focused on 12 areas of faculty academic development, including teaching, learning and assessment, graduate education, research and development, computer applications in education, health communication skills and e-learning.
\end{abstract}

Results: Teaching, learning and assessment skills were top priorities (30\%), followed by graduate education (29\%), research and development (28\%), computer applications in education (28\%), health communication skills $(26 \%)$ and e-learning (25\%). Priorities were emphasized in the following order of concern: teaching, learning and assessment $(60 \%)$, computer application in education (59\%), research and development (54\%), student support (54\%), graduate education $(53 \%)$ and quality improvement in health care (53\%).

Conclusions: Greater emphasis was on teaching, learning and assessment, research and development, and graduate education. These were believed to be areas needed to become a globally competitive 'university of tomorrow'. Interestingly, academic writing, paper publications, application of simulation in health science, leadership and administration, and mentoring were of least concern.

Keywords: Faculty Development, Academic Priorities, Health Colleges, Kingdom Saudi Arabia

\section{Introduction}

Since its establishment in $1957(1377 \mathrm{H})$, King Saud University (KSU) has gone through many changes academically and physically.

It is one of the premier universities in the Kingdom, striving to become a 'university of tomorrow' comparable to the global best institution (KSU Strategic Plan, 2010). The strategy is clearly outlined in the KSU

Strategic Plan 2010 document.

\footnotetext{
${ }^{1}$ College of Applied Medical Sciences, King Saud University

${ }^{2}$ Office of the Vice Rector for Health Specialties, King Saud University

${ }^{3}$ College of Dentistry, King Saud University

${ }^{4}$ College of Medicine, King Saud University

Corresponding Author:

Prof. Dr. Mohd Zahedi, College of Applied Medical Sciences, King Saud University, Riyadh KSA.

Vice-President, Medical and Health Sciences Cluster,

Management \& Science University, Shah Alam 40100

Selangor, Malaysia

Email:zahedimzd@yahoo.com.my, mdaud@ksu.edu.sa
}

The university was ranked as $200^{\text {th }}$ by $Q S$ (2011), 236 ${ }^{\text {th }}$ by Webometric (2012) and as $300^{\text {th }}$ by Shanghai Rankings (2012). King Saud University is ranked first in the Arab world (Shanghai Rankings 2012), and is the University of First Choice among Saudi students. To push the University forward, innovative academic and research strategies are being implemented. The strategy builds on the combined effort and support of the faculty, the professional community, the industries and the alumni. It is noted that many KSU graduates are in key positions in the country and overseas.

Within King Saud University, the medical and health colleges (MHC) are known for their academic excellence, and function as a service center for the local community. The MHC adapted well to changes in health education and health delivery. Studies have shown the relationship between a good health delivery system and excellence in health education (Barzansky et al., 1995). 
Colleges need to innovate their health education delivery methods if they are to maintain excellence. One innovation introduced by KSU is the establishment of the office of the Vice Rector for Health Specialties (VRHS). All MHCs are placed under the purview of the VRHS, who strategizes and manages the overall development of the health colleges, thus ensuring excellence and professionalism within MHC. The VRHS organises workshops, seminars, overseas visits, and exchanges of MHC professionals. These initiatives enhance MHC faculty expertise as teachers and health professionals. Studies on teaching and learning elsewhere have shown significant changes in the teaching ability of faculty who participated in development workshops compared to those who did not (Gibson \& Campbell, 2000; Busari et al., 2006). In addition, there is a positive association between students' satisfaction in teaching and learning with having experienced faculty members (Zianee et al., 2004). In the period 2009/2010 alone, the Deanship of Skill Development (DSDKSU, 2010) of King Saud University had successfully sent 4634 faculty members to more than 204 seminars and workshops in the Kingdom and overseas (KSU Strategic Plan, 2010)

Having reviewed the above, we conducted a study among faculty members of MHC King Saud University. It was to gauge faculty commitments and readiness to engage in KSU initiatives towards academic and research excellence. Respondents were asked to list priorities in faculty development, and also to indicate if they were ready to participate in workshops or seminars initiated by the Office of VRHS. The questionnaire was posted online via the KSU e-services., Face-to-face interviews were also made available to respondents.

\section{Methods}

The questionnaire was posted on the university e-services (https://forms.ksu.edu. sa/skills). It consisted of three (3) parts, covering (i) academic background of respondents, (ii) training priorities, and (iii) their readiness to participate in seminars and workshops. Responses were scored on a scale of (1) strongly agreed, (2) agreed, (3) disagreed, and (4) no opinion. The instrument was pretested before being posted; responses were recorded and analyzed using the SPSS Statistical Package. All faculty members had access to the questionnaires. Only $7 \%$ of $\mathrm{MHC}$ faculty responded to the survey.

Respondents were faculty members and academic support staff of MHC King Saud University. Their participation in the survey was voluntary. Prior to the survey, they were informed of the study by their respective MHC Skill Development Committee representatives.

\section{Results}

Ninety-eight (98) faculty members participated in the survey, representing $7 \%$ of the faculty and academic support staff of MHC. Sixty-seven percent of the respondents were Saudis, and 59\% were female (Table 1). Most had served KSU for less than 5 years (54\%), and were Assistant Professors (34\%), academic instructors (19\%), Associate Professors (19\%), Professors (17\%), and medical consultants (10\%). Sixty-three percent had PhD, and $19 \%$ had Bachelor's or Master's degrees (Table 2). Thirty-seven percent of the respondents were MHC administrators. Distribution of respondents within colleges was as follows: College of Applied Medical Sciences (32\%), College of Dentistry (29\%), College of Pharmacy (18\%), College of Medicine (10\%), College of Nursing (4\%), and the Riyadh College of Health Sciences $(3 \%)$. Most of the respondents $(67 \%)$ had a teaching load of less than 12 hours per week. We noted that some of the clinicians (23\%) did more than 12 hours of clinical teaching per week. Sixty-eight percent and sixty percent of the clinicians and nonclinicians respectively had no postgraduate teaching responsibilities. Eighty-eight percent of the respondents had 1-3 ongoing research projects, and $85 \%$ had published 1 3 papers in 2008/2009

Table 1: Respondent Profile: Demographic and Academic Designation

\begin{tabular}{|c|c|c|c|c|c|c|c|c|}
\hline & $\mathrm{n}$ & $\begin{array}{l}\text { Saudi } \\
(\%)\end{array}$ & $\begin{array}{l}<5 \text { Yrs } \\
\text { KSU (\%) }\end{array}$ & $\begin{array}{l}\text { Asst.Prof } \\
(\%)\end{array}$ & Assoc.Prof & Prof. & Consultants & Instructors \\
\hline Male & 40 & $23(58)$ & $18(45)$ & $19(48)$ & $6(15)$ & $5(13)$ & 0 & $10(25)$ \\
\hline Female & 58 & $43(74)$ & $35(60)$ & $14(24)$ & $13(22)$ & $\begin{array}{l}12 \\
(21)\end{array}$ & $10(17)$ & $9(16)$ \\
\hline Total & 98 & $66(67)$ & $53(54)$ & $33(34)$ & 19 (19) & $\begin{array}{c}17 \\
(17)\end{array}$ & $10(10)$ & 19 (19) \\
\hline
\end{tabular}


Table 2: Respondent Profile: Academic Qualification

\begin{tabular}{lccccc}
\hline & $\mathrm{n}$ & $\mathrm{PhD}$ & Subspecialty/Consultants & Bachelor/instructors & Clinicians \\
Male & 40 & $25(63)$ & $5(13)$ & $10(25)$ & $13(33)$ \\
Female & 58 & $37(64)$ & $12(21)$ & $9(16)$ & $25(43)$ \\
Total & 98 & $62(63)$ & $17(17)$ & $19(19)$ & $38(39)$ \\
\hline
\end{tabular}

On a score scale of 4 , Teaching, learning and assessment were the top priority $(30 \%)$, followed by graduate education (29\%), research and development (28\%), computer applications in education (28\%), health communication skills (26\%) and e-learning (25\%). However when the response scale is narrowed (Table 3), combining 'strongly agreed' and 'agreed' as one score scale, teaching, learning and assessment dominated $(60 \%)$, followed by computer application in education (59\%), research and development (54\%), student support
(54\%), graduate education (53\%) and quality health care $(53 \%)$. When faculty development priorities between the male and females academic were compared, significant differences were observed only in the following areas: teaching, learning and assessment (males 85\%, females $100 \%, X^{2}=6.84$, $\mathrm{P}=0.05$ ), student support (males $80 \%$, females $97 \%, \quad X^{2}=5.39, \quad P=0.05$ ), computer application (males $75 \%$, females $94 \%$, $\left.\mathrm{X}^{2}=6.46, \mathrm{P}=0.05\right)$, and quality improvement in health care (males $78 \%$, females $97 \%, X^{2}=6.82$, $\mathrm{P}=0.05)$.

Table 3: Respondent Responses to Questionnaire items (respondents, $n=98$ )

\begin{tabular}{lcc}
\hline Item & \% Score Scale (4)* & \% Score Scale \\
$(2)^{\star *}$ & 60 \\
Teaching \& Learning & 30 & 53 \\
Graduate Education & 29 & 54 \\
Research \& Development & 28 & 59 \\
Computer in Education & 28 & \\
Health Communication Skills & 26 & 54 \\
E-Learning & 25 & 53 \\
Student Support System & 20 & \\
Quality Health Care & 21 & \\
Acad.Writing \& Publication & 17 & \\
Simulation Technology in Health Education & 20 & 15 \\
Leadership and Administration & 18 & \\
Mentoring & & \\
\hline
\end{tabular}

*Score Scale (4): Strongly Agreed (4), Agreed (3), Disagreed (2), No Opinion (1)

${ }^{* *}$ Score Scale (2): Strongly Agreed and Agreed (2), Disagreed (1)

Responses indicated that the main concern of faculty members were teaching, learning and assessment, computer application in education, research and development, students support, graduate education, and quality health care. Also, the survey indicated that academic writing and publications, application of simulation in health science, leadership and administration, and mentoring were the least concern of the respondents. The study demonstrated that faculty members regard teaching, learning and assessment, research and development and graduate education as their main responsibilities. Computer technology was recognized as a tool in effective teaching and learning.
It is noted that our respondents are academics of good standing, being active in research and having had published papers in refereed academic journals, and participated in seminars and workshops in the Kingdom or overseas. When queried on seminar or workshop participation preferences, $70 \%$ male and $69 \%$ female faculty preferred work-day seminars over weekends (Tables 4 and 5) Half-day seminars were most preferred (44\%), followed by a one-day (34\%) or two-day (14\%) event, and only $8 \%$ preferred more than two (2) days. The morning half of the day was the time of choice $(61 \%)$, followed by evening (18\%) and afternoon (15\%). 
When asked to indicate their seminar/workshop venue of choice, most (73\%) preferred the university campus. However, if the seminars/workshops had to be off-campus, $82 \%$ would rather have them within Riyadh; only $12 \%$ percent preferred international venues. Most female academics (91\%) preferred Riyadh for conferences and workshops.

Table 4: Respondent Responses to Participation in Seminars and Workshops: Duration

\begin{tabular}{lcclcccc}
\hline & $\mathrm{n}$ & $\begin{array}{l}\text { Venue : } \\
\text { Campus } \\
\%(\mathrm{n})\end{array}$ & $\begin{array}{l}\text { Preference: } \\
\text { Workday } \\
\%(\mathrm{n})\end{array}$ & $\begin{array}{l}\text { Preference: } \\
\text { Half-day } \\
\%(\mathrm{n})\end{array}$ & $\begin{array}{l}\text { Preference: } \\
\text { One-day } \\
\%(\mathrm{n})\end{array}$ & $\begin{array}{l}\text { Preference: } \\
\text { Two-day } \\
\%(\mathrm{n})\end{array}$ & $\begin{array}{c}\text { More } \\
\text { than } \\
\text { days }\end{array}$ \\
$\%(\mathrm{n})$ \\
Male
\end{tabular}

Table 5: Respondent Responses to Participation in Seminars and Workshops: Time

\begin{tabular}{lccllll}
\hline & $\mathrm{N}$ & $\begin{array}{l}\text { Venue : } \\
\text { Campus } \\
\%(\mathrm{n})\end{array}$ & $\begin{array}{l}\text { Preference: } \\
\text { Morning }\end{array}$ & $\begin{array}{l}\text { Preference: } \\
\text { Afternoon }\end{array}$ & $\begin{array}{l}\text { Preference: } \\
\text { Evening }\end{array}$ & $\begin{array}{l}\text { Preference: } \\
\text { None } \\
\%(\mathrm{n})\end{array}$ \\
Male & 40 & $19(19)$ & $28(11)$ & $30(12)$ & $43(17)$ & 0 \\
Female & 58 & $91(53)$ & $85(49)$ & $5(03)$ & $2(01)$ & $7(5)$ \\
total & 98 & $73(72)$ & $61(60)$ & $15(15)$ & $18(18)$ & $5(5)$ \\
\hline
\end{tabular}

\section{Discussion}

The King Saud University Vision 2030 envisions itself as a world class university and a leader in building Saudi knowledge society (KSU Strategic Plan, 2010). The vision challenges the $\mathrm{MHC}$ to formulate strategies to realize these aspirations. MHC integrates advanced technologies into teaching and learning processes, thus enhancing faculty teaching skills. Our study probes MHC faculty members on their thoughts on specific areas of academic development. Several random preliminary interviews were conducted with faculty members. Perceived priority areas were identified and selected. These formed the basis of the questionnaire used in the study. It is to help decision makers to strategize academic development initiatives.

Our observation indicated that faculty members in general, were most concerned about teaching, learning and assessment. Studies elsewhere have shown that assessment of health student competency is difficult, sometimes frustrating, and has always been the main concern of faculty members (Kane, 1992).

Other areas of concern were computer application, research and development, student support, graduate education, and quality improvement in health care. Though computer technology, as demonstrated by simulation in teaching, was recognized as an effective tool in teaching and learning, e-learning ironically did not get the attention it deserves in this survey.
Female academics were especially concerned about teaching, learning and assessment. Teaching represents the traditional responsibilities of university teachers, and faculty members were very much interested in strengthening their expertise in this area. Surprisingly, academic writing and publication were of least concern to faculty members, followed by simulation in teaching, mentoring, academic leadership and administration. Most of our respondents were academics of good standing, were active in research and had published papers in refereed academic journals. Similarly, academic leadership and administration were not considered high priority though $18 \%$ of survey participants were Associate Professors, Professors (17\%), medical consultants (12\%), and MHC administrators (37\%). It demonstrated the need to rethink the present practice of in-house recruitment of $\mathrm{MHC}$ administrators. It is common practice at most universities to recruit senior academics and professors to management posts. Traditionally in most cases, it is regarded as a form of promotion or recognition of their academic or research work.

Faculty members were sensitive to student needs. They ranked student support high on their priority list. Forty-seven percent of the respondents supported students mentoring, which is known to promote teaching and learning satisfaction to both faculty and students. Studies have shown that mentored students 
spent more time on academic activities, thus ensuring effective training process (Rose et al., 2005). Educational processes created opportunities for students to develop mentoring relationships with faculty members (McNamara et al., 2008). However in the same study, they noted gender differences in strategies in establishing mentor-mentee relationships. Female students were more passive compared to their male counterparts (McNamara et al., 2008). Gender issues were important as it was demonstrated above. A quick perusal through our faculty development data suggests that males and females academics are best dealt with separately. While all agreed that teaching, learning and assessment were their main priority, their priorities in other areas differed. Female faculty members would like to see more attention given to student support, quality health care and computer technology in education.

During the period 2008/2009 and 2009/2010, a total of 2,588 and 4,634 KSU faculty members respectively were sent for training within the Kingdom or overseas (VRQD-KSU (2010) and DSD-KSU (2010) quoted in KSU Strategic Plan (2010). These initiatives strengthen the expertise and professionalism of the KSU academic staff. Our study showed that faculty members were keen and eager to participate in training workshops, though most (73\%) preferred that workshops be conducted in Riyadh and only $12 \%$ preferred overseas. Within Riyadh, the KSU campus was preferred $(73 \%)$ over other venues in the city. And seventy eight $(78 \%)$ of the respondents indicated that they would like the workshops or seminars to be either half or one day. The time of choice for workshops and seminars was during the morning half of the day, preferably during week-days; only $31 \%$ preferred weekends. There were no significant differences in opinions between the male and female faculty members on the management of the workshops and seminars. We suggest $\mathrm{KSU}$ event managers take note of our findings because these could be a useful guide, encouraging participation at workshops and seminars. Studies elsewhere noted that attendance is directly associated with venue accessibility in terms of dates, location and their relevance (Smith, 2002). Similarly, management endorsement and professional growth opportunities are other factors associated with seminar-workshop attendance (Weaver et al., 2004; Smith, 2002).

In conclusion, academics within MHC acknowledged the importance of faculty development, and had rated teaching, learning and assessment as top priority. It was to some extent an expected response. The MHC is fast expanding and staff recruitment is a continuous exercise. Recruited faculty members are highly qualified in their field of specialization, but they are usually not trained as teachers. Academic qualification of faculty alone is not enough for satisfactory outcome in teaching and learning (Davis et al., 1994). Faculty must be trained in teaching and learning, also in research and innovation, and academic writing. Faculty members irrespective of their expertise understood the need for exposure on pedagogical method (Gibson \& Campbell, 2000; Amin et al., 2009). Specific faculty training areas need to be clearly identified to satisfy both the faculty development needs and student learning satisfaction. Studies have shown that student professional behavior is largely influenced by faculty's commitment in the teaching and learning processes (Stith et al., 1998). Thus, cooperation across sectors within MHC (and $\mathrm{KSU}$ ) is needed. Training programs are better served if they are properly coordinated between the various KSU units responsible for faculty development.

\section{Acknowledgement}

The help and cooperation of the Medical and Health Colleges, the Deanship of Skill Development, and the Deanship of E-Learning are gratefully acknowledged. Special thanks to the Vice Rectorship for Health Specialties and King Saud University for the facilities and services rendered.

\section{References}

Amin, Z., Khoo, H.E., Chong, Y.S., Tan, C.H., Goh, P.S., Samarasekaran, D.D., Chan Y.H. \& Koh, D.R. (2009) A multi-institutional survey on faculty development needs, priorities and preferences in medical education in an Asian Medical School, Medical Education, 14, pp.16, [Online], Available at: http://www.med-ed-online-org .

Busari, J.O., Scherpbier, A.J., Van der Vleuten, C.P. \& Essed, G.G. (2006) A two-day teacher-training program for medical residents: investigating the impact on teaching ability, Advances in Health Sciences Education Theory and Practice,11, pp. 133-144.

Barzansky, B., Jouns, H.S. \& Etzal, S.L. (1995) Education programs in US medical education schools (1994-1995), Journal of American Medical Association, 274, 9, pp.716-722.

Davis, W.K., Oh, M.S., Anderson, R.M., Gruppen, L. \& Nairn, R. (1994) Influence of highly focused case on the effect of small-group facilitators' content expertise on students learning and satisfaction, Academic Medicine, 69, 8, pp. 663-669. 
DSD-KSU (2010) Deanship of Skill Development KSU, Annual Reports. King Saud University, Riyadh KSA, KSU (unpublished).

Gibson, D.R. \& Campbell, R.M. (2000) Promoting effective teaching and learning: hospital consultants identify their needs, Medical Education, 34, pp. 126130.

Kane, M. (1992) The assessment of professional competence, Evaluation and the Health Professions, 15, pp. 163-182.

KSU-Strategic Plan (2010) King Saud University Strategic Plan 2030. King Saud University, Riyadh KSA, KSU Publications.

McNamara, M.C., McNeil, M.A. \& Chan, J. (2008). A pilot study exploring gender differences in residents' strategies for establishing mentoring relationships, Medical Education, 13, p. 7. [Online] Available at: http://www.med-ed-online-org.

Rose, G.L., Rukstalis, M.R. \& Schuckit, M.A. (2005) Informal mentoring between faculty and medical students, Academic Medicine, 80, pp. 344-348.
Smith, L.S. (2002) Increasing RN attendance at community-wide CE programs, Journal of Nurses in Staff Development, 18, pp.36-40.

Stith, J.S., Butterfield, W.H., Strube, M.J., Deusinger, S.S. \& Gillespie, D.F. (1998) Personal, inter personal and organizational influences on students satisfaction with clinical education, Physical Therapy; 78, 6, pp. 635-45.

Weaver, B., Rosenfeld, G.C., Karen, N.K., Menna, J., Walsh, J.B. \& Jackson, J.R. (2004) Low attendance by basic science educators at medical education meetings, Journal of Nurses in Staff Development, 16, pp. 306-11.

VRDQ-KSU (2010) Self-Study Report (SSR). Vice Rectorate for Development and Quality, King Saud University Riyadh KSA, KSU Publications.

Zianee, V., Ahmadinejad, Z. \& Morravedji, A.R. (2004) An evaluation on medical students satisfaction with clinical education and its effective factors. Medical Education, 9, pp.8 [Online] Available at: http://www.med-ed-online-org. 